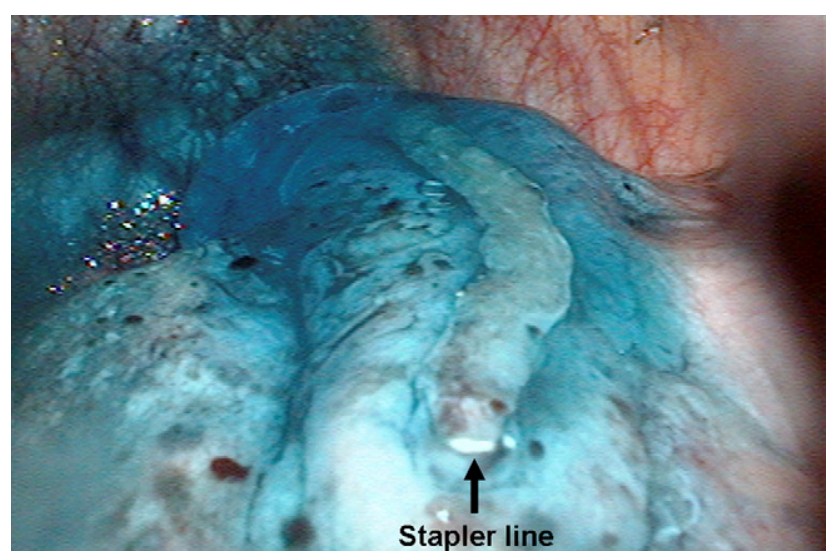

FIGURE 2. Thoracoscopic view of the transparent blue seal after spray application of PleuraSeal lung sealant at the site of pulmonary tissue resection (with an endoscopic linear stapler).

When PEG and trilysine solutions are mixed, they polymerize almost instantaneously to form a 3-dimensional absorbable hydrogel. ${ }^{4}$ The polymerization is a gentle process on tissue with no exothermic reaction and minimal tissue response. The rapid influx of the liquid form of PEG and trilysine into tissue crevices enables hydrogel formation that has a strong mechanical bond with underlying tissue. The combination of high cohesive strength and flexibility of the hydrogel renders it the capability to accommodate natural expansion and contraction of the underlying lung tissue. ${ }^{5}$

For proper spray application during thoracoscopic procedures, the MicroMist applicator tip should be held $2 \mathrm{~cm}$ from the target site, and the sealant should be applied in a way to create a 1- to 2-mm-thick hydrogel. The application site should be prepared by removing all blood and fluids before spraying. When compared with the injection technique, the spray applicator enables uniform spraying of the sealant to cover a larger surface area and enables paucity between spray intervals without clogging of the applicator tip or denaturing of the sealant components.

PleuraSeal has received the CE mark (Conformité Européenne) for lung sealing and has been available in the European Union since 2006; however, at present, it is not for sale in the United States. A single-use application kit costs approximately $€ 400$. PleuraSeal offers a novel offthe-shelf synthetic biodegradable lung sealant that can be applied as a visible blue-colored spray and can be used as a prophylactic adjunct in thoracoscopic lung procedures.

\section{References}

1. Fabian T, Federico JA, Ponn RB. Fibrin glue in pulmonary resection: a prospective randomized, blinded study. Ann Thorac Surg. 2003;75:1587-92.

2. Torchiana DF. Polyethylene glycol based synthetic sealants: potential uses in cardiac surgery. J Card Surg. 2003;18:504-6.

3. Shingel K, Di Stabile L, Marty JP, et al. Inflammatory inert poly(ethylene glycol)protein wound dressing improves healing responses in partial- and full-thickness wounds. Int Wound J. 2006;3:332-42.

4. Royce Hynes S, McGregor LM, Ford Rauch M, et al. Photopolymerized poly (ethylene glycol)/poly(L-lysine) hydrogels for the delivery of neural progenitor cells. J Biomater Sci Polym Ed. 2007;18:1017-30.

5. Almany L, Seliktar D. Biosynthetic hydrogel scaffolds made from fibrinogen and polyethylene glycol for 3D cell cultures. Biomaterials. 2005;26:2467-77.

\title{
The application of nitinol thermoreactive Flexigrips for late post-cardiac surgery sternal instability
}

\author{
Hunaid A. Vohra, MRCS, MD, Robert N. Whistance, MRCS, Marcob Bolgeri, MRCS, and \\ Geoffrey M. K. Tsang, MD, FRCS(CTh), Southampton, United Kingdom
}

Median sternotomy is the most frequently used incision in cardiac surgery. Sternal instability is a chronic complication

\footnotetext{
From the Wessex Cardiothoracic Centre, Southampton University Hospitals NHS Trust, Southampton, United Kingdom.

Disclosures: None.

Received for publication Nov 22, 2008; accepted for publication Dec 6, 2008; available ahead of print May 11, 2009.

Address for reprints: Geoffrey M. K. Tsang, MD, FRCS(CTh), Wessex Cardiothoracic Centre, Southampton University Hospitals NHS Trust, Southampton General Hospital, Tremona Road, Southampton, United Kingdom (E-mail: geoff.tsang@suht.nhs.uk). J Thorac Cardiovasc Surg 2010;139:497-9 0022-5223/\$36.00

Copyright $(2010$ Published by Elsevier Inc. on behalf of The American Association for Thoracic Surgery

doi:10.1016/j.jtcvs.2008.12.003
}

following malunion or nonunion. This is traditionally managed by reopening the sternum completely, removing fractured or loose metalwork, and rewiring. Reoperation may be hazardous due to adhesions, adjacent right ventricle, and patent grafts. We report for the first time the application of nitinol thermoreactive Flexigrips (Preasidia SRL, Bologna, Italy) in the management of sternal instability without the need to enter the mediastinum.

\section{CLINICAL SUMMARY \\ Patient 1}

An 80-year-old man with $\mathrm{FEV}_{1}$ of $0.8 \mathrm{~L}$ was admitted with unstable angina. After an urgent coronary angiogram, he underwent quadruple coronary artery bypass grafting $(\mathrm{CABG}$; 

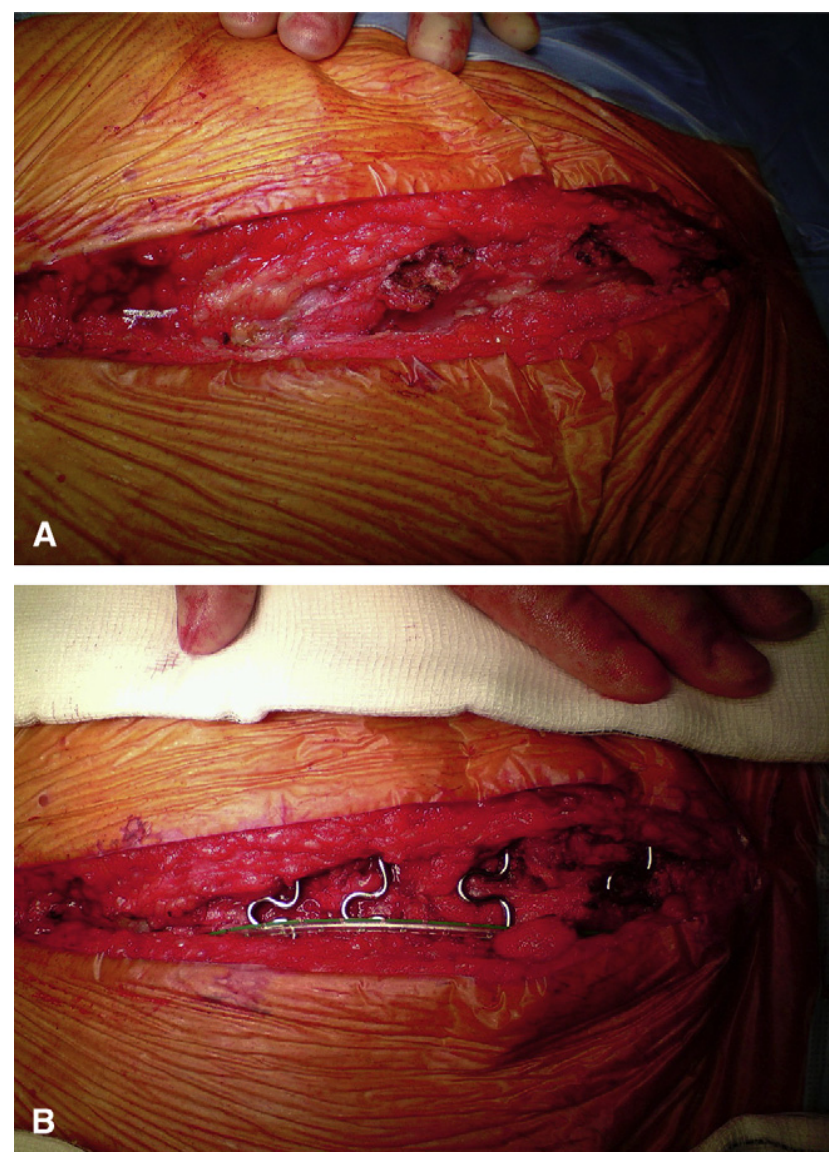

FIGURE 1. A, The unstable, nonunited sternum. The wires have been removed. The head of the patient is on the right. B, The 4 Flexigrips in place. Note the redivac drain in the wound. The head of the patient is on the right.

left internal thoracic artery to left anterior descending artery, reversed long saphenous vein [LSV] to second diagonal, LSV to second obtuse marginal, and LSV to posterior descending artery) with cardiopulmonary bypass. The chest was closed with 7 stainless steel wires. Postoperative recovery was uneventful, and the patient was discharged home 1 week after surgery. One year later, he presented with symptomatic unstable sternum. The patient was readmitted for sternal reconstruction. Thoracic epidural catheter was inserted. At surgery, 6 of the sternal wires were found to be fractured, and the 2 halves of the sternum were nonunited (Figure 1, A). All the fractured wires were removed. The fibrous union between the sternal edges was not divided. Flexigrips were inserted by incisions made through the external intercostal ligaments and internal intercostal muscles as close as possible to the sternum with diathermy in the third, fourth, and fifth intercostal spaces bilaterally. The edges of the sternum were approximated and the distance between the incisions measured with calipers. This determined the size of Flexigrip required (20-40-mm width). In this fashion, 4 Flexigrips ( 1 to the manubrium and 3 to the body) were applied with the help of an applicator. The patient was extubated immediately after the operation. The patient was discharged 5 days after surgery.

\section{Patient 2}

A 72-year-old man had triple CABG for unstable angina. The chest was closed with 7 stainless steel wires. Postoperative recovery was uneventful, and the patient was discharged home 5 days after surgery. When the patient was seen during follow-up 8 months later, the 2 halves of the sternum were freely mobile. A chest radiograph revealed fractured wires. Surgery was performed to stabilize the sternum. The broken wires were removed, and 4 Flexigrips were inserted as described above with an excellent result (Figure $1, B)$. The patient was discharged 7 days after surgery.

\section{DISCUSSION}

We have reported for the first time the application of Flexigrips for the correction of late postoperative sternal instability. The major benefit of using Flexigrips is that they can be placed without the need to dissect underneath the sternum, avoiding the risk of damaging the underlying grafts and the right ventricle. Nitinol (NIckel TItanium Naval Ordinance Laboratory) is a metallic alloy of nickel $(55 \%)$ and titanium $(45 \%)$ that exhibits extraordinary properties of shape memory and superelasticity. At temperatures below $10^{\circ} \mathrm{C}$, nitinol is malleable and can be molded into shape as required. Heating the alloy to $>27^{\circ} \mathrm{C}$ causes it to begin to return to its initial shape. Nitinol is chemically more stable, less corrosive, and more biocompatible than stainless steel. ${ }^{1}$ Flexigrips are C-shaped prostheses used in the closure of median sternotomy incisions. Flexigrip is then placed in iced sterile saline solution for several minutes. The clip can then be manipulated, allowing the ends to be inserted through the openings in the intercostal spaces. By warming the Flexigrip to body temperature with sterile saline solution at $45^{\circ} \mathrm{C}$, the clip returns to its original shape, approximating the sternal edges. Due to elasticity, Flexigrips do not cut through osteoporotic bone, and as they do not completely encircle the sternum, they can be applied and removed with greater ease. Nitinol does not interfere with magnetic resonance imaging. Flexigrips have been shown to reduce sternal dehiscence as compared with steel wiring after cardiac surgery. ${ }^{2}$

In the setting of postsurgical instability, however, placement can be cumbersome with the presence of nonuniform tissue on the superior surface of the sternum, which may need to be shaved or resected for symmetrical and flat positioning of the Flexigrips. Also, insertion through the openings in the intercostal spaces, especially on the left side, may injure the adherent left lung, leading possibly to an air leak and pneumothorax. This occurred in the first patient, and we placed a redivac drain at the site of the air leak and 
also inserted a left intercostal chest drain. Routine postrepair chest radiograph is advised. In our practice, we recommend the routine use of a sternal support for the following 3 months. We believe that correction with Flexigrips is a safer and simpler way of dealing with post-cardiac surgery sternal instability and should be used more frequently.

\section{References}

1. Centofanti P, La Torre M, Barbato L, Verzini A, Patane F, di Summa M. Sterna closure using semirigid fixation with thermoreactive clips. Ann Thorac Surg. 2002;74:943-5.

2. Negri A, Manfredi J, Terrini A, Rodella G, Bisleri G, El Quarra S, Muneretto C Prospective evaluation of a new sternal closure method with thermoreactive clips. Eur J Cardiothoracic Surg. 2002;22:571-5.

\title{
A novel solution for repeated migration of an implantable cardiac defibrillator
}

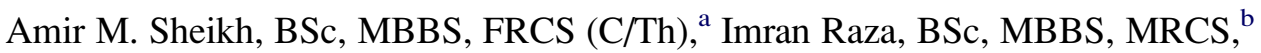 \\ Simon Charles Edwin Sporton, BSc, MBBS, MD, MRCP, ${ }^{\mathrm{c}}$ and Kulvinder S. Lall, MBBS, FRCS, ${ }^{\mathrm{d}}$ Toronto, \\ Ontario, Canada, and Kent and London, United Kingdom
}

Migration and extrusion of pacemakers and implantable cardiac defibrillators (ICDs) has been reduced over the years as devices have become smaller and lighter. However, this phenomenon still occurs. We present a case in which this problem occurred repeatedly, leading to a novel easily fashioned solution for this previously more common problem.

\section{CLINICAL SUMMARY}

A 69-year-old man was referred to the cardiothoracic surgeons for help with repositioning of a migrating ICD in 2007. A dual-chamber ICD was originally inserted in 2004 for sustained ventricular tachycardia. The pulse generator was placed in a subpectoral pocket. The pulse generator subsequently migrated laterally and was repositioned in 2005 to a more medial subpectoral pocket. The patient returned with pain and threatened erosion to the inferior part of the male breast fold. The patient's recurrent problem had a number of predisposing factors. He was overweight at $89 \mathrm{~kg}$ and had signs of gynecomastia owing to spironolactone therapy. He had a history of chronic obstructive airway disease with

\footnotetext{
From the Division of Cardiac Surgery, ${ }^{\text {a }}$ Toronto General Hospital, Toronto, Ontario,

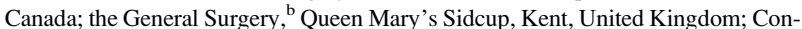
sultant in of Cardiology ${ }^{\mathrm{c}}$ and Cardiothoracic Surgery, ${ }^{\mathrm{d}}$ Barts and The London NHS Trust, London, United Kingdom.

At the time of this report, Dr Raza's affiliation was Cardiothoracic Senior House Officer, St Bartholomew's Hospital, Department of Cardiothoracic Surgery, West Smithfield, London, United Kingdom.

Disclosures: None.

Received for publication Oct 4, 2008; revisions received Nov 25, 2008; accepted for publication Dec 19, 2008; available ahead of print March 9, 2009.

Address for reprints: Imran Raza, BSc, MBBS, MRCS, Queen Mary's Sidcup, Frognal Ave, Sidcup, Kent, DA14 6LT, United Kingdom (E-mail: imrani@yahoo.com). J Thorac Cardiovasc Surg 2010;139:499-501

$0022-5223 / \$ 36.00$

Copyright (c) 2010 by The American Association for Thoracic Surgery doi:10.1016/j.jtcvs.2008.12.015
}

home oxygen therapy and inhaled steroid medication, with multiple enteral steroid courses. He also had a history of ischemic heart disease for which he had undergone a coronary artery bypass graft many years previously.

There was no evidence of twiddler's syndrome, as has been described in many previous case reports of ICD migration or failure requiring repositioning. ${ }^{1-3}$ The ICD itself was still functional and there was no evidence of lead dislodgment, fracture, or malfunction from chest radiographs and from ICD interrogation.

With the patient under general anesthesia, the ICD was approached via the left deltopectoral scar from previous insertions. The generator and leads were easily located and dissected free. The generator was detached and the leads were checked and found to be functioning normally. The opportunity was taken to insert a new generator.

Prolene mesh (Ethicon, Inc, Somerville, NJ) and 2-0 polypropylene sutures were used to fashion a pouch around the ICD. The mesh was folded around the ICD and the two open edges were sutured with a horizontal running mattress suture, followed by a continuous over-and-over suture (Figures 1 and 2). The mesh was ensured to be tight around the lead-box connections (Figure 3). The pouch and the enclosed ICD were returned to the subpectoral space, ensuring the sutured edges of the pouch were facing superiorly. With multiple interrupted 2-0 polypropylene sutures applied to the edge of the pouch, the pouch was sutured to the underlying subpectoral fascia. The overlying pectus muscle was closed with interrupted $2-0$ absorbable braided suture, and the remaining layers were closed in routine fashion.

The patient was discharged home without complication and on last consultation, approximately 6 months after the procedure, was well and described no problems with the ICD. Specifically, there were no problems with ICD displacement or discomfort. 